\title{
The development of soft skills among students during a business game
}

\author{
Mikhail V. Vinichenko, Alexander V. Melnichuk, Sergey A. Makushkin \\ Department of Personnel Management and Personnel Policy, Russian State Social \\ University, Russia.
}

\begin{abstract}
The growth of competitiveness of university graduates in the labor market is growing due to the development of soft skills. The purpose of this article was to identify the most rational form of practical training for the development of soft skills among students. The paper used an analysis of the effectiveness of the application of the author's methodology for conducting a business game. The empirical basis was the results of a sociological survey of students based on the results of practical exercises in the form of the business game "Search for Truth". The opinion poll was attended by 487 students from 39 study groups. As a result, it was found that this form allows students to increase the development efficiency of creativity, the ability to go out to innovative knowledge, communication skills, the ability to work in a team, fairly evaluate their colleagues, leadership qualities, and stress resistance. The growth of excitement in achieving victory, a sense of responsibility for collective actions as part of multilingual and multicultural groups is revealed. Ways of neutralizing negative phenomena during and after classes are proposed. The study showed that the business game contributes to the development of soft skills among students.
\end{abstract}

Keywords: Soft skills; business game; efficiency; educational process; innovation. 


\section{Introduction}

The effectiveness of student learning in modern higher education largely depends on the professionalism of teachers and the technologies that they use in the training. Their activities should ensure that students are taught the skills that are most in demand on the labor market (Buley et al, 2018). Recently, there has been a tendency to increase the importance of soft competencies in business and government institutions. The most difficult to develop and strengthen such ones as creativity (Matraeva, et al, 2020), communicative skills in a multilingual and multicultural team, the ability to work in a team, and fairly evaluate their colleagues (Nikiporets-Takigawa, 2018). They seek to solve this problem through the use of gaming techniques, the gamification of education (Marti-Parreno et al, 2016; Lumsden et al, 2016; Vinichenko et al, 2019), and the use of coaching (Dunbar, 2019).

In the academic environment, there is a search for creating conditions for the exchange of knowledge, experience in improving the effectiveness of training (Al-Kurdi, et al, 2019), creating favorable conditions for learning (Laseinde et al, 2019). The issues of using artificial intelligence are considered (Shakhovska, et al, 2019), ways to solve the problem of employment are discussed (Demchenko et al, 2017).

There are various approaches and techniques for identifying and developing soft competencies. However, a universal technique does not exist. A search is underway for the most acceptable approaches and methods for achieving the learning objectives. This study seeks to become a link in the chain of success in the development of soft competencies among students.

\section{Methodology}

The purpose of the study is to identify the most rational form of practical training for the development of soft competencies. In order to identify the most optimal form of conducting practical exercises, a technique was developed. It was tested in the operating mode during the pedagogical experiment for 12 years with various changes and additions based on the identified problem areas. In its present form, it is called the "Search for Truth." In a formal simplified form, this is the technology "Question-answer with assessment by an expert group". The study group is divided into two opposing groups and an expert group. They are seated in a special way (Figure 1). Opposing groups are located opposite each other (face-toface), an expert group is between them. 




Figure 1. Options for a business game. Source: Designed by the authors

Opponent groups organize themselves in a team with a leader and choose their name. They prepare 5-10 questions on the basis of material studied during the lecture. Questions are written on paper in duplicate. One copy is given to the expert group for evaluation. It takes 15-30 minutes.

Then the competition begins. One member of the first opposing group asks a question. The second opposing group prepares an answer within 1-3 minutes. After the collective development of the answer option, one of the members of the second group answers the question posed. The expert group online estimates both the question and the answer and notes in the table (Table 1).

Then the second opposing group asks its own question and receives the answer in the same way. This procedure continues until all questions are asked. Then the expert group summarizes the points of the opposing groups for both questions and answers, then announces the winner. The group that scored the most points wins. The expert group also determines the best question and the best answer. Then the teacher evaluates the work of all groups, starting with the opponents. He also analyzes the quality of questions and answers, points to the positive aspects and shortcomings. 
Table 1. Expert evaluation table discussion.

\begin{tabular}{|c|c|c|c|c|c|c|c|c|c|}
\hline \multicolumn{5}{|c|}{1 opposing group } & \multicolumn{5}{|c|}{2 opposing group } \\
\hline \multicolumn{5}{|c|}{ questions } & \multicolumn{5}{|c|}{ questions } \\
\hline & expert & expert & expert & $\begin{array}{c}\text { Overall } \\
\text { score }\end{array}$ & & expert & expert & expert & $\begin{array}{c}\text { Overall } \\
\text { score }\end{array}$ \\
\hline 1 & & & & & 1 & & & & \\
\hline 2 & & & & & 2 & & & & \\
\hline 3 & & & & & 3 & & & & \\
\hline 4 & & & & & 4 & & & & \\
\hline 5 & & & & & 5 & & & & \\
\hline \multicolumn{5}{|c|}{ answers } & \multicolumn{5}{|c|}{ answers } \\
\hline 1 & & & & & 1 & & & & \\
\hline 2 & & & & & 2 & & & & \\
\hline 3 & & & & & 3 & & & & \\
\hline 4 & & & & & 4 & & & & \\
\hline 5 & & & & & 5 & & & & \\
\hline total & & & & & total & & & & \\
\hline
\end{tabular}

Source: Designed by the authors. 
(Assessment of questions: 0 points - there is a direct answer in the text of the lecture; 1 point - causes discussion on the topic; 2 points - leads to a systematization of knowledge; 3 points - forms innovative knowledge; Assessment of answers: 0 points - the answer is taken in the text of the lecture; 1 point - discusses the topic of the lecture; 2 points - systematizes the acquired knowledge; 3 points - forms the answer in the form of innovative knowledge).

During the pedagogical experiment, 185 classes were held with 39 study groups (487 students). They were, 27 multicultural groups and 12 multilingual and multicultural groups. At the end of the course, soft skills were evaluated with students, and a survey was conducted on the effectiveness of this form of training. Students took part in a sociological survey to identify the effectiveness of the development of soft skills during the business game "Search for Truth."

During the course, feedback was organized to improve the preparation and conduct of the business game. The teacher took into account the wishes of students to improve the class.

Many skills were measured using this technique. There is a difficulty in measuring skills such as creativity. You can't rate it in points. We always rated it as "Amazing!" and encouraged by praise and appreciation.

The article draws conclusions based on student surveys during and after the course. Statistics were given at the end of the course. The rating scale was based on the Likert methodology using a 5-point system. Also, these data were discussed at a focus group with the involvement of teachers, specialists, and methodologists.

\section{Results and Discussion}

In the course of the study, it was found that when studying the "Human Resource Management" course using a business game as a form of conducting practical (seminar) classes, the effectiveness of the development of creativity, the ability to enter innovative knowledge among students increased by $27 \%$, communication skills - by $41 \%$, and the ability to work in the team - by $43 \%$, fairly evaluate their colleagues - by $35 \%$, leadership qualities - by $23 \%$, stress resistance - by $31 \%$.

Sustainability of skills was determined after completing the course, the university using feedback from graduates and their employers.

Resistance to stress was determined by constantly monitoring students' behavior during the game and in everyday life.

During the survey of students, it was possible to establish that the development of excitement, the desire to win in a business game, which activated students' creative potential, became characteristic features. There was an increase in maturity in assessing the essence of the 
issues discussed and the ability to conduct a discussion correctly. The sense of responsibility for collective actions was aggravated, leadership qualities were formed during the allocation of an informal leader, as well as trust in team members. The most active and ambitious students, even being the leader of the group, sought to get into the expert group, considering membership in it to be of a higher status. Students of different cultures, religions, languages sought to combine their efforts in achieving victory over the opposing group. Sometimes it was necessary to use a double translation: English-French-Russian for a more complete understanding of the essence of the question or answer.

The emergence of negative emotions and attitudes towards their opponents against the background of the duration of competition after the end of the business game was noted as problem areas. Sometimes sharp discussions arose not on the topic of a business game, but on the quality of the assessment of questions and answers. It should be noted that the main part of the negative phenomena manifested itself in the initial stage of practical training in this form of a business game. In subsequent classes, the negative consequences were eliminated by replacing the experts, changing the composition of the opposing groups, and explanatory work of the teacher. A rare occurrence (less than 1\%) was the refusal of students to participate in the next business game due to poor knowledge of the language in which the business game was conducted (Russian, English).

The most effective ways of developing soft competencies among students were identified:

- $\quad$ Free, creative atmosphere.

- Involving students in the search for urgent problems, competitive ideas.

- $\quad$ Providing an opportunity to assess the essence of issues and speaking skills.

- Development of the ability to find the right answer quickly.

- Skillful use of the students' potential of various faiths, races, ethnic groups, language groups.

- Identification of students' leadership qualities required in managerial activities.

- Formation of an effective creative team.

\section{Conclusion}

Improving the effectiveness of the educational process in the interests of business lies in the application of modern pedagogical technologies. The use of gaming methods contributes to the development of soft competencies in demand on the labor market. The search for the most rational form of conducting practical exercises for the development of soft competencies made it possible to identify one of them - the business game "Search for Truth". Its 
implementation allows you to develop such competencies as the development of creativity, the ability to reach innovative knowledge among students, communication skills, the ability to work in a team, fairly evaluate your colleagues, leadership skills, stress resistance. The solution of identified problem areas is in the field of pedagogical skills, the level of development of soft competencies. Using innovative forms of conducting classes will improve the quality of training.

\section{References}

Al-Kurdi, O.F., El-Haddadeh R, Eldabi, T. (2019). The role of organizational climate in managing knowledge sharing among academics in higher education. International Journal of Information Management. 50: 217-227.

Buley Natalia, Demchenko Tatiana, Ilina Irina, Vinichenko Mikhail (2018). Development of samomarketing competences in students in the interactive lessons. 34th International Scientific Conference on Economic and Social Development - XVII International Social Congress (ISC-2018): Economic and Social Development. Book of Proceedings. Editors: Aleksander Maloletko, Natasa Rupcic, Zoltan Baracskai. 2018: 411-419.

Demchenko T.S., Peter Karácsony, Ilina I.Y., Vinichenko M.V., Melnichuk A.V. (2017). Self-Marketing Of Graduates Of High Schools And Young Specialists In The System Of Personnel Policy Of The Organization. Modern Journal of Language Teaching Methods (MJLTM), 7(9): 58-65.

Dunbar, D. (2019). Can university senior managers take lessons from sports coaching? Perspectives: Policy and Practice in Higher Education. 23(2-3): 101.

Laseinde, T., Oluwafemi, I., Pretorius, J.-H., Oluwafemi, J. (2019). The impact of work environment in concurrence to productivity in higher institutions. AHFE International Conference on Social and Occupational Ergonomics, 2019; Washington D.C.; United States. Advances in Intelligent Systems and Computing. 970: 309-320.

Lumsden, J., Edwards, E.A., Lawrence, N.S., Coyle, D., Munafo, M.R. (2016). Gamification of cognitive assessment and cognitive training: a systematic review of applications and efficacy. JMIR Serious Games. 4(2), e11. DOI: 10.2196/games.5888

Marti-Parreno, J., Segui-Mas, D., Segui-Mas, E. (2016). Teachers`attitude towards and actual use of gamification. 2nd International Conference on Higher Education Advance (HEAd`16), 21-23 June 2016, Valencia, Spain, Social and Behavioral Science, 228, 682688.

Matraeva, A.D., Rybakova, M.V., Vinichenko, M.V., Oseev, A.A., Ljapunova, N.V. (2020). Development of Creativity of Students in Higher Educational Institutions: Assessment of Students and Experts. Universal Journal of Educational Research. 8(1): 8-16. http://www.hrpub.org/download/20191230/UJER2-19513842.pdf

Nikiporets-Takigawa, G. (2018). Youth and youth policy in the UK: Post-brexit view. Sovremennaya Evropa. 1 (80) : 47-58.

Shakhovska, N., Vovk, O., Holoshchuk, R., Hasko, R. (2019). The Student Training System Based on the Approaches of Gamification. 2nd International Conference on Computer 
Science, Engineering and Education Applications, (ICCSEEA 2019). Advances in Intelligent Systems and Computing. 938: 579-589.

Vinichenko M.V., Taridi K. Ridho, Peter Karacsony, Li N. P., Gundeea S. Narrainen, Chulanova O.L. (2019). The feasibility and expediency of gamification activities in higher education. International Journal of Education and Practice, 7(4): 459-468. DOI: 10.18488/journal.61.2019.74.459.468. 